\title{
Derived Rock Attributes Analysis for Enhanced Reservoir Fluid and Lithology Discrimination
}

\author{
Udo, K. I. ; Akpabio, I. O. ; Umoren, E. B. \\ Geophysics Research Group, Department of Physics, University of Uyo, Uyo, Nigeria \\ Email:kufreudo@uniuyo.edu.ng
}

\begin{abstract}
Elastic properties of rocks were derived from well logs and 3D post-stack seismic from Onshore Niger Delta through rock physics modelling and LamdaMuRho (LMR) seismic inversion. These rock properties were analyzed to map hydrocarbon bearing sands as well as the different fluid types trapped in them. Pimpedance, S-impedance, Vp/Vs ratio, porosity, LamdaRho ( $\lambda \rho)$ and MuRho $(\mu \rho)$ were derived from well logs using appropriate relations. These rock parameters were analyzed in cross-plots space and used to determine which of them constitutes better indicators of pore fluids and lithology. Inversion of the post-stack seismic data was also carried out to generate Acoustic Impedance, Lamda-Rho and Mu-Rho volumes. Data slices of the inverted volumes were then generated to further study the characteristics of the identified hydrocarbon bearing intervals. Results showed that the cross-plot of Lambda-Rho versus Mu-Rho from all the wells yielded best discrimination between fluids and lithology and the values of Acoustic Impedance (1.665 $x \quad 10^{4}-$ $2.742 \times 10^{4}((f t / s) *(g / c c))$, MuRho $\left(4.31-17.17\left(f t / s^{*} g / c c\right)^{2}\right)$ and LamdaRho $\left(14.9-35.5\left(f t / s^{*} g / c c\right)^{2}\right)$ from data slices of the inverted seismic volumes validated the results. The results also showed that medium to high values of MuRho $\left(>5.0\left(\mathrm{ft} / \mathrm{s}^{*} \mathrm{~g} / \mathrm{cc}\right)^{2}\right)$ were indicative of clean sands while lower values of LambdaRho(< $\left.23.5\left(\mathrm{ft} / \mathrm{s}^{*} \mathrm{~g} / \mathrm{cc}\right)^{2}\right)$ correlated well with areas containing hydrocarbons.
\end{abstract}

Keywords: Acoustic impedance, LamdaMuRho, seismic inversion, Reservoir fluid, cross-plots.

\section{Introduction}

Accurate description of a reservoir in terms of lithology and fluid content is an important factor in reducing the risk involved in hydrocarbon exploration. Lithology and reservoir fluid studies based on conventional interpretation paradigms, such as low $V_{\mathrm{P}} / V_{\mathrm{S}}$ values indicating gas presence, that do not incorporate an understanding of rock physics always lead to biased interpretations. Ratios in particular can be misleading because there is ambiguity about whether an anomalous ratio is driven by the numerator or denominator. As a classic gas indicator, low $V_{\mathrm{P}} / V_{\mathrm{S}}$ values are interpreted to be driven by a decrease in $V_{\mathrm{P}}$ associated with gas replacing brine in a rock. Using Lamé impedance terms $\lambda \rho$ and $\mu \rho$, however, provides an alternative interpretation template that does not use only ratios and can improve insight into rock properties (Close, et. al., 2016).

Goodwayet al (1997) earlier showed that the Lame parameter terms $\lambda \rho$ and $\mu \rho$ are good pore fluid indicators and can be calculated using the relations

$$
\begin{aligned}
& \lambda \rho=I_{p}^{2}-C I_{s}^{2} \\
& \mu \rho=I_{S}^{2}
\end{aligned}
$$

where the Lame parameters are $\lambda$ (which is sensitive to pore fluid) and $\mu$ (which is sensitive to matrix connectivity but is independent of the pore fluid). $\mathrm{I}_{\mathrm{P}}$ and $\mathrm{I}_{\mathrm{S}}$ are $\mathrm{P}$ - and $\mathrm{S}$ - wave impedances respectively and $\mathrm{C}$ is a constant.

The LMR method proposed by Goodwayet al (1997) was based on Fattiet al's 1994 approximation for the Zoeppritz equation. P-wave reflectivity $\Delta \mathrm{Ip} / \mathrm{I}_{\mathrm{p}}$ and S-wave reflectivity $\Delta \mathrm{I}_{\mathrm{S}} / \mathrm{I}_{\mathrm{S}}$ can be estimated. From Pwave and S-wave reflectivity, the P-wave and S-wave impedance can be computed by the inversion process. By using the impedance attributes: Ip and Is, Goodwayet al. (1997) proposed two attributes: $\lambda \rho$ and $\mu \rho$ for discrimination of fluid and lithology change: It was observed by Goodwayet al, (1997) that $\lambda \rho$ and $\mu \rho$ are more orthogonal in crossplot space than Ip versus Is, which enables us to use $\lambda \rho$ versus $\mu \rho$ as an effective indicator to separate the gas sand from wet sand or shale.

Quantitative interpretation of pre-stack seismic-inversion attributes has become industry standard and is essential both in prospect mapping during hydrocarbon exploration and in reservoir characterization during appraisal and production. There are several different approaches but the common goal of all the methods is to extract information about lithology, reservoir quality, and pore fluids from the prestack seismic amplitudes for reservoir characterization (Chopra and Castagna, 2014). The onshore Niger Delta has gradually assumed the status of a matured oil and gas producing province. A lot of bypassed reservoirs could still be won from these old oilfields using newer approaches. One of such tools is rock physics/seismic inversion and one of its primary goals is to enhance the understanding of the physical properties of the reservoir. Usually, at the location of a 
drilled well, we have measurements that give us a good idea of the elastic and physical properties of the subsurface rocks (Velocity, Density, Lithology, Porosity, etc.). However, to understand these properties away from the well, we have to rely on seismic data volumes. Rock physics studies now help us to link these properties to the seismic data and infer their variation in a lateral and vertical sense (Sayers and Chopra, 2009). In effect, by studying the physical rock properties at known hydrocarbon bearing intervals at well locations, one can use the results to delineate other potential hydrocarbon zones away from wells.In this study, the key deliverable is to integrate rock physics and seismic data inversion to predict rock and fluid properties, for reservoir characterization of parts of the Niger Delta away from existing wells so as to create new exploration and development opportunities in the field.

\section{Field Geology And Characteristics}

The Niger Delta basin is situated at the southern end of Nigeria boarding the Atlantic Ocean and extends from about longitude $3^{0} \mathrm{E}$ to $9^{0} \mathrm{E}$ and latitude $4^{0} 3^{\mathrm{I}} \mathrm{N}$ to $5^{0} 2^{\mathrm{I}} \mathrm{N}$. Petroleum occurs throughout the Agbada formation of the Niger Delta. However, several directional trends form an oil rich belt having the largest field and lowest gas to oil ratio (Doust and Omatsola, 1990). The belt extends from the northwest offshore area to the southeast onshore along a number of north-south trends in the area of Port Harcourt. The position of the oil rich belt to oil prone marine source rocks deposited adjacent to the delta lobes, suggests that the accumulation of these source rocks was controlled by pre-tertiary structural sub-basins, related to basement structures (Haack,1997).The field used in this research has several stacked reservoirs including the HD5000 reservoir analyzed in this study. The HD5000 reservoir is within the depth of $6347 \mathrm{ft}$ to $6530 \mathrm{ft}$. The water saturation values of HD5000 reservoir is found to be $8 \%$. The inline and xline range of the wells used in this work are shown in the base map below (Figure 1). N001, N002 and N003 (Well A, Well B and Well C respectively) are located at the north eastern part of the Field.

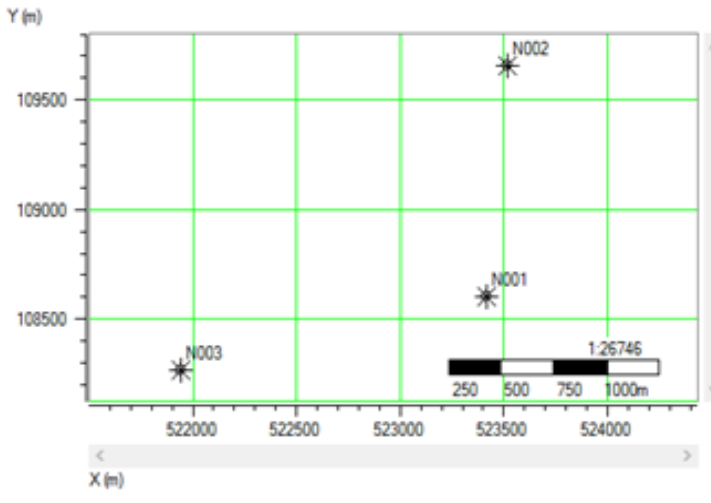

(a) 1D view

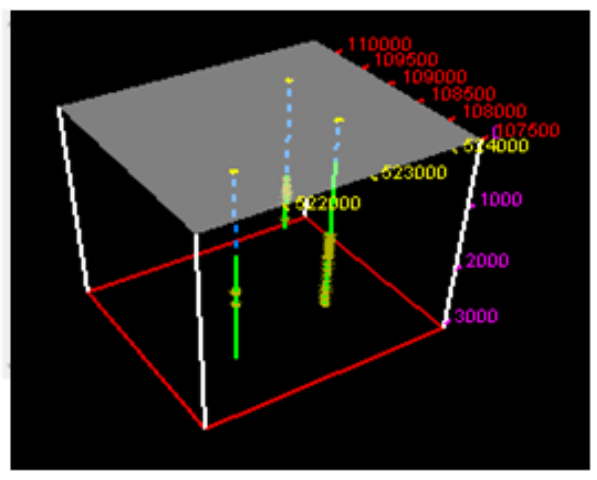

(b) 3D view

Figure 1. Base map of the Study Area

\section{Methodology}

The data used for this work include well logs from three wells: N001, N002, and N003 (also labelled as well A, Well B and Well C respectively) and a 3D post-stack seismic data from onshore Niger Delta basin. The work was carried out in three stages, namely; i. Well-log editing and modelling,

ii. Rock properties derivation and cross plotting,

iii. Seismic modeling and attribute generation from seismic data using model-based inversion.

Lambda-rho $(\lambda \rho)$ and Mu-rho $(\mu \rho)$ attributes were extracted from the inverted seismic volumes. These attributes provide information about the rock's compressibility and rigidity which, in turn, depend upon pore fluid type and matrix properties of rocks. Other attributes considered in this work include acoustic impedance, density, porosity and $\mathrm{Vp} / \mathrm{Vs}$ ratio. These attributes were computed from both $\log$ and seismic data. In the end, the results from the three stages were analyzed in other to delineate hydrocarbon prospect and pore fluid discrimination. The well log data, seismic and rock attribute cross-sections were analyzed using Hampson Russel software.

\section{Crossplots Of Derived Rock Attributes}

Rock attributes were estimated from the input log data using rock-physics algorithm. These attributes include Vp/Vs ratio, porosity (from density), lamdarho, murho, S-impedance and P- impedance.

We first used the Castagna's relation for S-wave to calculate the shear wave velocity. 


$$
v_{s}=c_{1} v_{p}+c_{2}
$$

With $\mathrm{C}_{1}$ and $\mathrm{C}_{2}=0.86190$ and -3845.1449 respectively.

P-impedance and $\mathrm{S}$-impedance were calculated using density, $\rho$, compressional wave velocity, $\mathrm{V}_{\mathrm{p}}$ and the derived shear wave velocity, $\mathrm{V}_{\mathrm{s}}$.

Where:

$$
\begin{gathered}
I_{p}=v_{p} \rho \\
I_{s}=v_{s} \rho
\end{gathered}
$$

LamdaRho, $\lambda \rho$ and MuRho, $\mu \rho$ were derived according to equations 1 and 2 , with the constant $\mathrm{C}=2$.

Cross plots of $\mathrm{Vp} / \mathrm{Vs}$ versus P-impedance ,P-impedance versus lamdarho, $\mathrm{Vp} / \mathrm{Vs}$ vs Lamda-Rho, $\mathrm{Vp} / \mathrm{Vs}$ versus porosity and MuRho versus LamdaRho were then carried out.

\section{Model Based Inversion}

The model-based inversion derives the impedance profile which best fits the modelled trace and the seismic trace in a least square sense using an initial guess impedance. Basically, this inversion resolves the reflectivity from an objective function and compares its RMS amplitude with the assumed reflectivity size. The wavelet is then scaled to compensate for the difference. This iterative process for updating the estimated reflectivity requires an initial impedance value. The initial impedance logs were obtained from the sonic and density $\log$ of the wells A, B and C. Each value of the mean impedance $\log$ obtained from the three wellscorresponded to the arithmetic sum of the individual impedance values for each well divided by the factor 3. During this process each well was stretched for matching the principal impedance contrasts with the formation tops associated with the HD5000 Formation at the tie location.

Wavelet extraction was first done. Wavelet analysis involves the estimation of a filter, which best fits well log reflection coefficients to the input seismic at well location. The wavelet extraction method applied is model supported, using seismic and well information. A wavelet is completely defined by its amplitude spectrum (amplitude versus frequency plot) and its phase spectrum (phase-shift versus frequency plot). Before applying seismic inversion, an accurate depth -to-time conversion must be performed in order to make the vertical scale of the well log acoustic impedance data match the vertical scale of the seismic data so as to allow spatial correlation. This is commonly known as well-to-seismic tie or correlation (figure 2). This process manually stretches or squeezes the log in order to improve the time correlation between the target $\log$ and the seismic attributes. Once any needed bulk shift and stretch are applied, the well log depth-to-time map will match the measured P-wave seismic times (White and Hu, 1998). This process simultaneously creates a composite trace from the seismic and a synthetic seismogram from the log (figure 2).

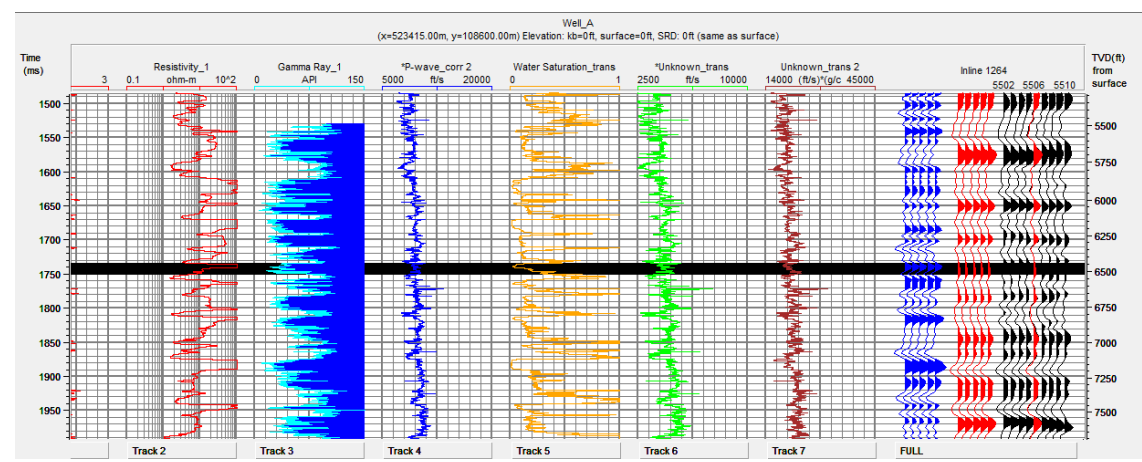

Figure 2: Well to seismic tie (well A- N001) showing to the right; synthetic trace (blue), seismic trace (black), and composite trace (red).Maximum correlation is 0.547 and zero time shift.

Models

Models were built for the Acoustic impedance, MuRho and LamdaRho volumes and used for the inversion (Figure 3). Using rock physics algorithm, rock attributes which includes lambda-rho, mu-rho rock property volumes were extracted from the pre-stack migrated seismic data. 


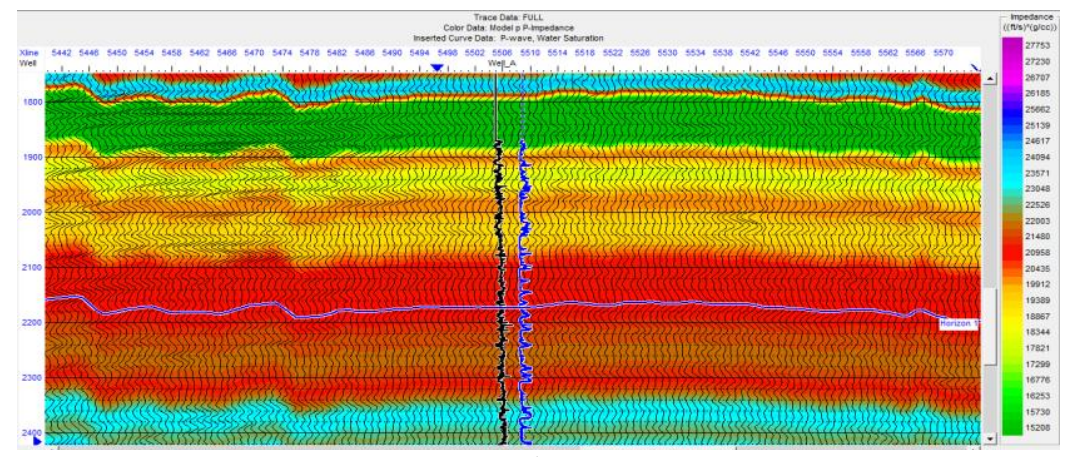

a)

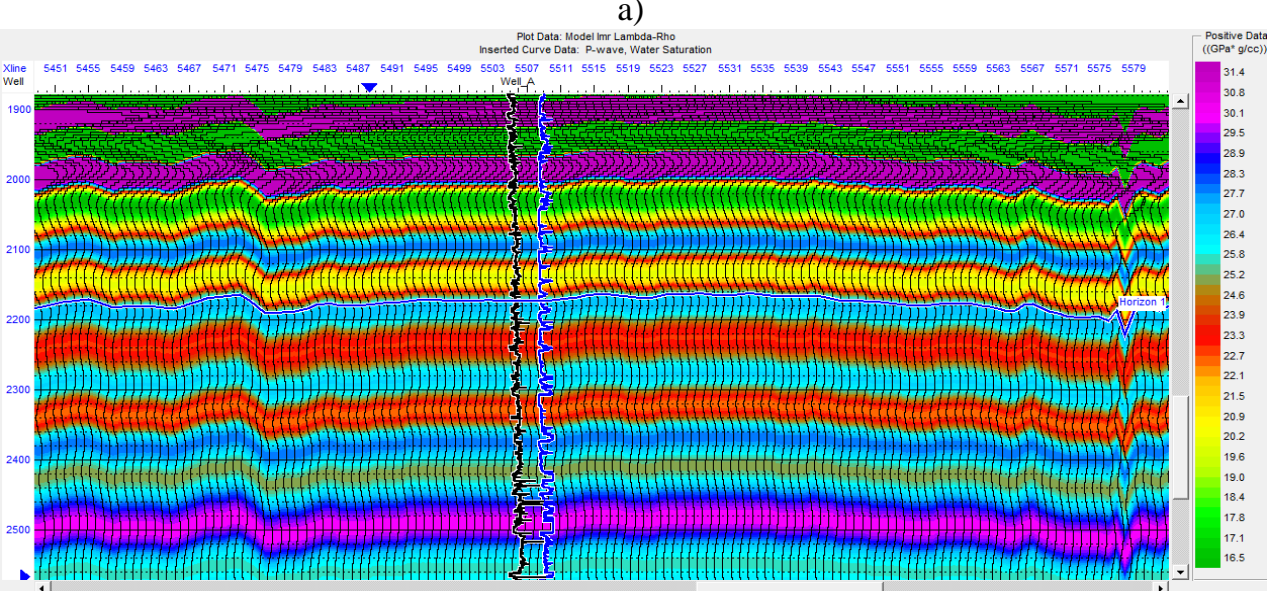

b)

Figure 3: Inversion modelsof (a) Acoustic Impedance (b) Lamda-Rho

\section{Results And Discussion}

The primary logs used include gamma ray, resistivity, caliper, and density logs which exhibit dominantly shale/sand/shale sequence. Other logs required were derived. Regions of low gamma ray, high resistivity and low water saturation are mapped as sand lithology, which are also known as regions of high hydrocarbon saturation (Figure 4a-c)

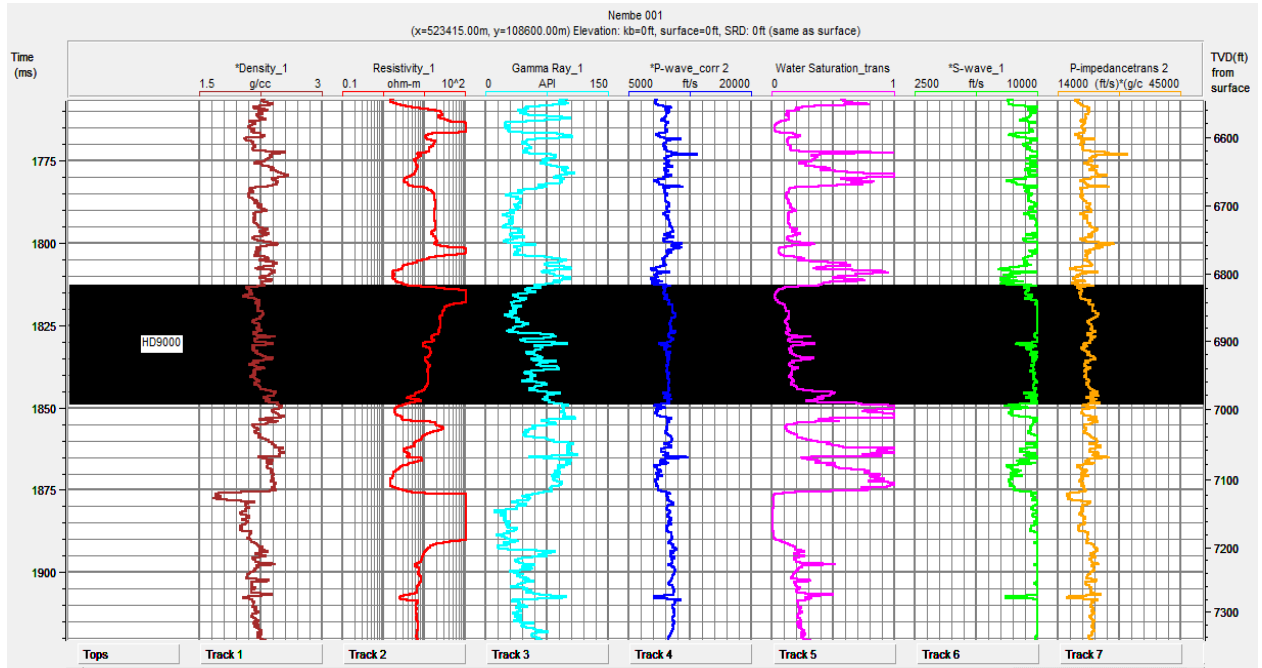

(a) 


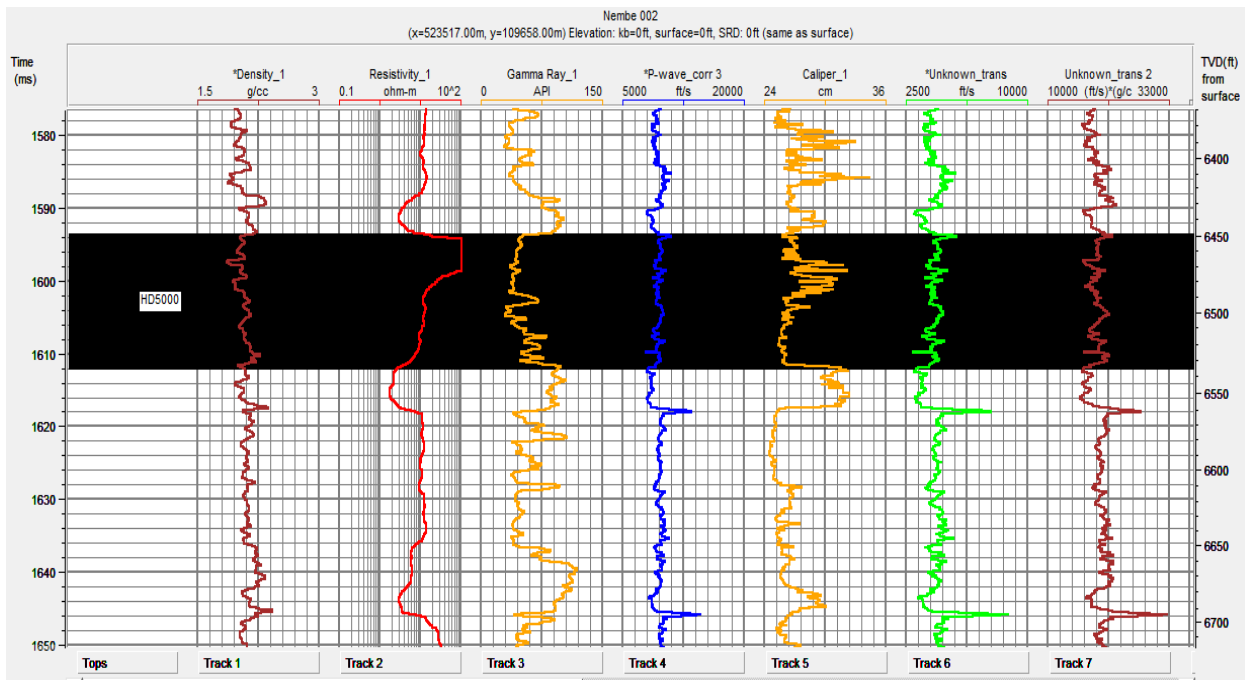

(b)

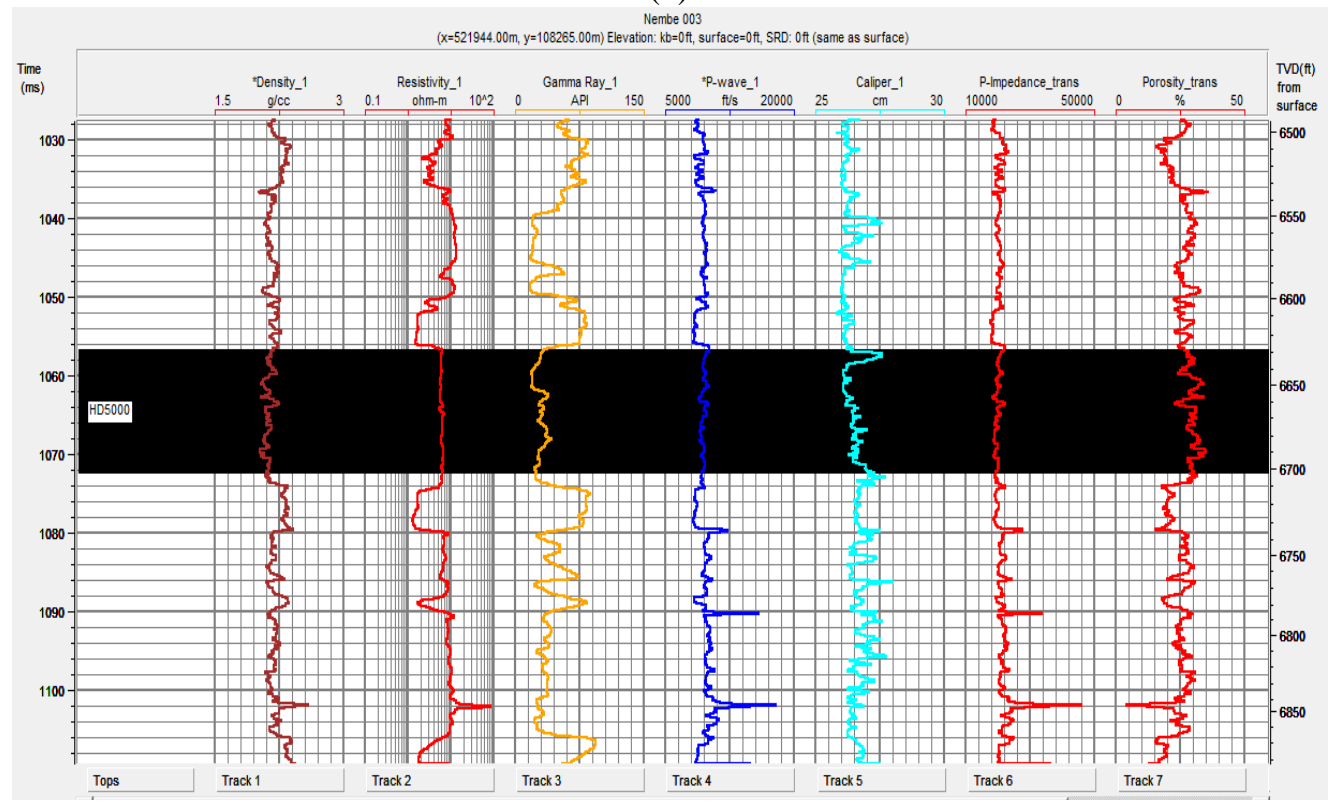

(c)

Figure 4 (a) Log suite of well A (N001) (b) log suite of well B (N002) (c) log suite of well C (N003)

\section{Crossplots Analysis}

\section{$V_{P} /$ Vs vs Acoustic Impedance cross plot}

The plot of Vp/Vs ratio against Acoustic impedance $\left(\mathrm{Z}_{\mathrm{p}}\right)$ (Figure 5) distinguishes the HD5000 reservoir into three zones namely; hydrocarbon zone (yellow ellipse), brine zone (blue ellipse) and shale zone (purple ellipse). Thiscrossplot shows fluid as well as lithology discrimination along the acoustic impedance axis, indicating that acoustic impedance attribute will better describe the reservoir conditions in terms of lithology and fluid content than $\mathrm{Vp} / \mathrm{Vs}$ ratio. 


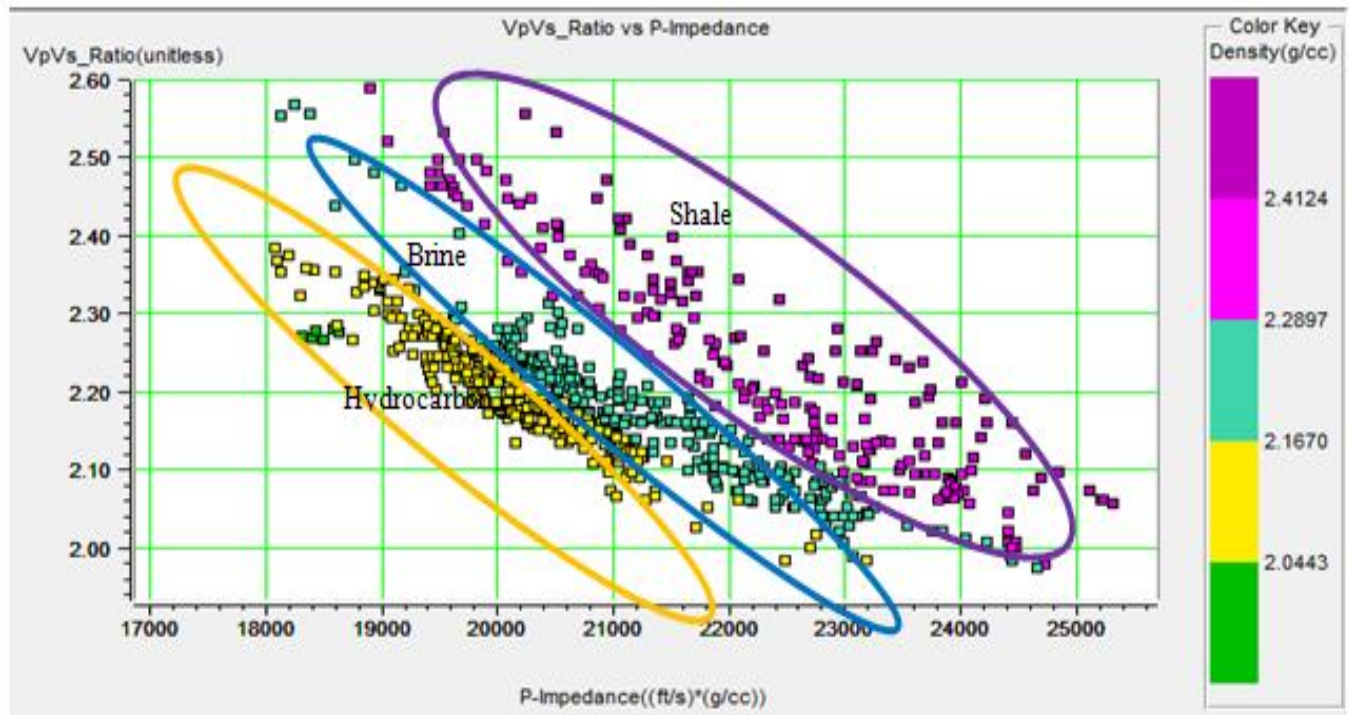

Figure 5 plot of Vp/Vs against P-Impedance

\section{Acoustic Impedance vs Lamda-Rho}

Crossplot of acoustic impedance (Ip) against lamdarho $(\lambda \rho)$ distinguishes the HD5000 sand into four zones (Figure 6), inferred to be gas (green), oil (red), brine (blue) and shale (purple). The lowest values of $\lambda \rho$ and $\mathrm{I}_{\mathrm{p}}$ associated with hydrocarbon are validated by low bulk density $(<2.2176 \mathrm{~g} / \mathrm{cc})$ as evidenced in the plot. The plot also indicates that both $I_{p}$ and $\lambda \rho$, show good discrimination in terms of fluid content. This is because high and low Ip suggest shale and sand respectively while the different fluid types in the sand lithology are clearly identified from brine to gas by the decreasing values of $\lambda \rho$.

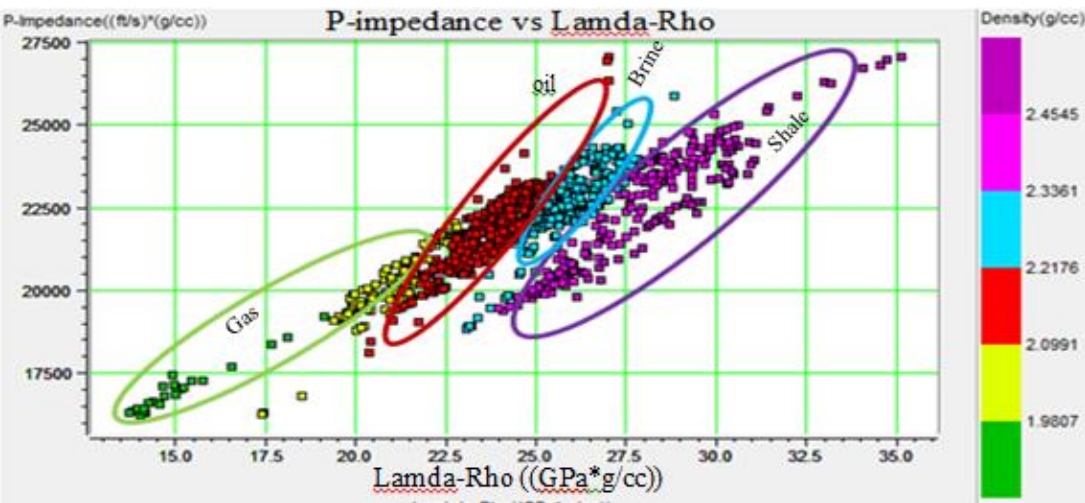

Figure 6: plot of P-impedance against Lamda-Rho

\section{Vp/Vs against Lambda-Rho}

Figure 7 shows the variation of $\mathrm{Vp} / \mathrm{Vs}$ against lambda-Rho (incompressibility) for sands and shale/sand/shale sequences. The plots are better aligned towards the lambda rho axis, thus validating lambda rho a better fluid discrimination tool. The purple ellipse describes shale zone, the blue describes brine sand, the red ellipse describes oil sand and the green describes gas zone. 


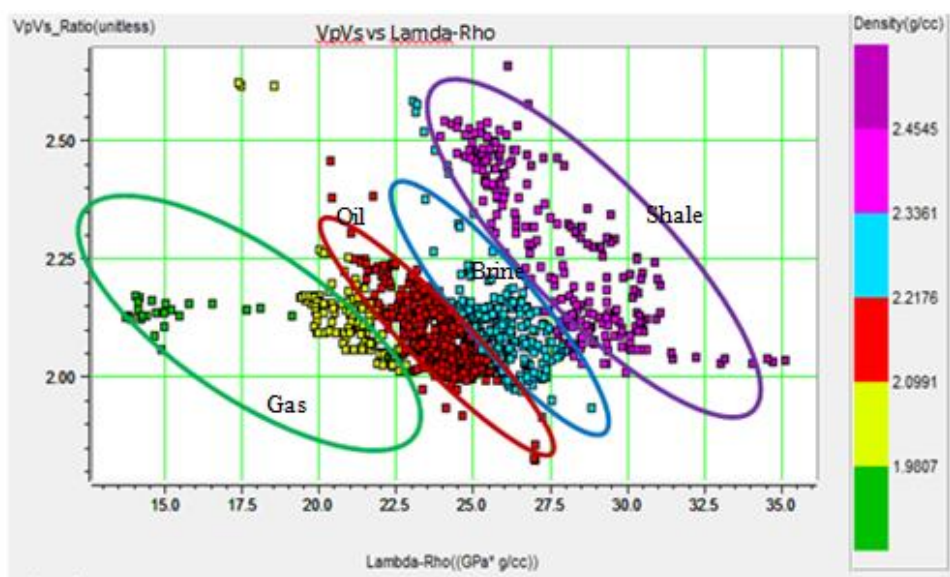

Figure 7. Plot of Vp/Vs against Lamda-Rho

\section{Cross plots of Vp/Vs ratio Versus Porosity}

Crossplot of Vp/Vs against Porosity distinguishes the HD5000 sand into four zones (Figure 8) inferred to be shale (purple), brine (blue), oil (red) and gas (yellow). The low valuesof $\mathrm{Vp} / \mathrm{Vs}$ and high Porosity (>30\%) associated with hydrocarboncharged sand are validated by low bulk density $(<2.2176 \mathrm{~g} / \mathrm{cc})$ as observed from the color code. The points plot significantly along porosity axis indicating that porosity is a good discrimination tool for lithology and fluid.

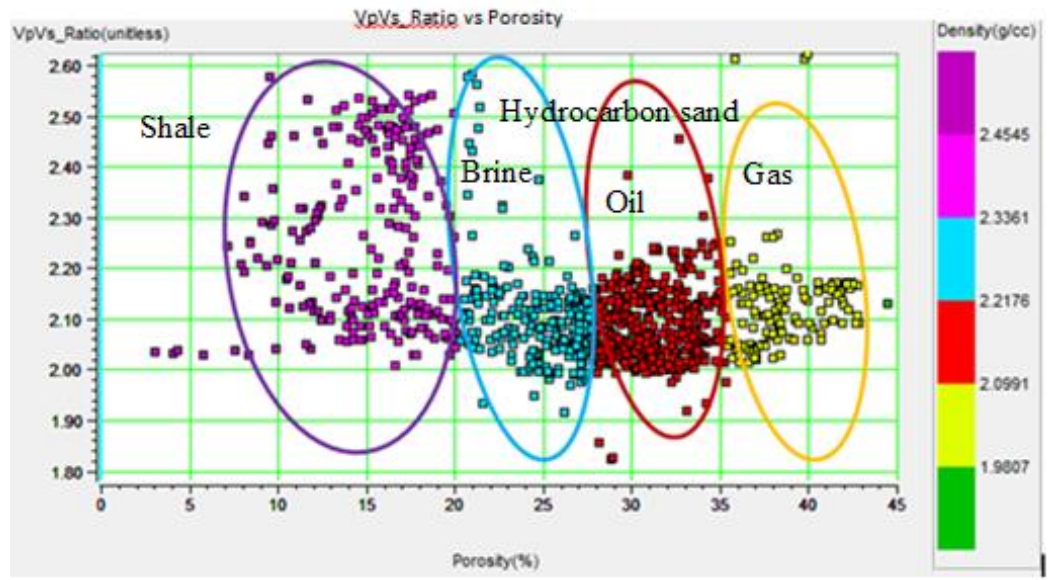

\section{Lambda-Rho Against Mu-Rho}

Figure 8. Plot of $\mathrm{Vp} / \mathrm{Vs}$ against porosity

Crossplots of murho $(\mu \rho)$ against lamdarho $(\lambda \rho)$ in Figure 9 also shows discrimination into four zones that can be inferred to be gas zone (green, oil zone (red), brine (blue) and shale (purple) validated by the density values. The plot indicates that $\lambda \rho$ is more robust than $\mu \rho$ in the discrimination of fluids, and that $\mu \rho$ values are relatively low for reservoir sands. The rock attributes found to be most robust in fluid discrimination based on the crossplot analysis were extracted from the $Z_{p}$ sections obtained from seismic inversion for reservoir characterization in terms of lithology and fluid. 


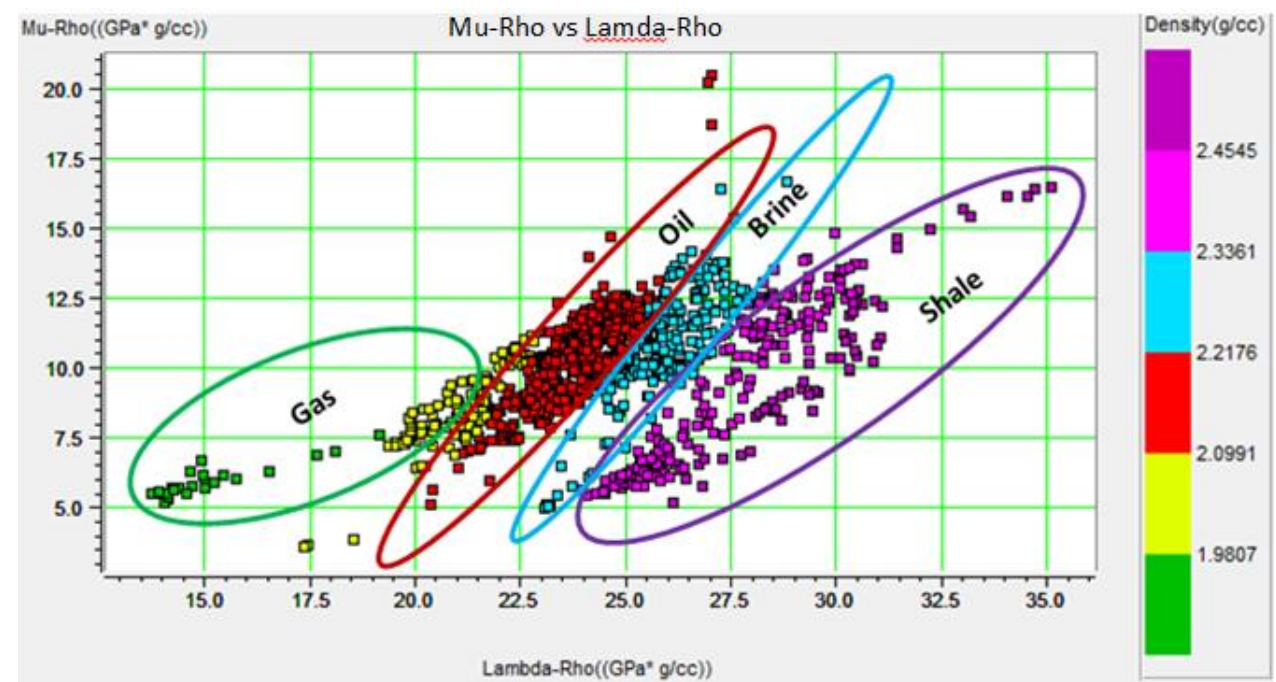

Figure 9: Plot of Mu-Rho against Lamda-Rho

\section{Seismic Inversion}

Inverted rock properties derived from model-based inversion, acoustic impedance and shear impedance were used to calculate rock attributes, using the $\lambda-\mu-\rho$ approach of Goodwayet al., (1997). The purpose of this analysis is to confirm the inference of the cross plots and to discriminate between lithology and fluids within the selected HD5000 reservoir sands.

\section{i. Acoustic Impedance, LamdaRho and MurhoCross-Sections}

Figure 10shows the acoustic impedance section derived from the 3D seismic data. The zones in red, blue and purple are in increasing order of acoustic impedances, while zones in green to yellow have low impedance values. The Lambda-rho attribute (figure 12) describes the incompressibility moduli of the lithologies. Low incompressibility values are well defined within the hydrocarbon charged zones. The embedding shalehas higher values of incompressibility.The Mu-rho attribute (figure 14) gives quantitative measure of the variation in rigidity and hence, lithology.

\section{ii. Acoustic Impedance,Lamda-Rho and Mu-rho Horizon Slices}

The data slices of acoustic impedance, lamd-rho and mu-rho are shown in Figures 11, 13 and 15 respectively. Acoustic impedance values range from $1.665 \times 10^{4}\left(\mathrm{ft} / \mathrm{s}^{*} \mathrm{~g} / \mathrm{cc}\right.$ ) (low) to as high as $2.742 \times 10^{4}$ $(\mathrm{ft} / \mathrm{s} * \mathrm{~g} / \mathrm{cc})$. It isgenerally sensitive to lithology and can fairly discriminate hydrocarbon charged sand from brine sand. The well locations in the slice exhibit relatively low acoustic impedance values especially around well A location and this confirms the results earlier obtained in the crossplots. Very low values of acoustic impedance $\left(1.665 \times 10^{4}\right.$ to $\left.1.783 \times 10^{4}(\mathrm{ft} / \mathrm{s})^{*}(\mathrm{~g} / \mathrm{cc})\right)$ were observed to the northern and southwestern parts of the well locations in the slice (Figure 11). These low values of acoustic impedance are associated with hydrocarbon saturated sands. Very high acoustic impedance values are observed to the south of the well locations, indicating depleted zones. Figure 13 shows $\lambda \rho$ slice at the mapped horizon. Lamdarho $(\lambda \rho)$ values ranges from 14.9 $\left(\mathrm{ft} / \mathrm{s}^{*} \mathrm{~g} / \mathrm{cc}\right)^{2}$ to as high as $35.5\left(\mathrm{ft} / \mathrm{s}^{*} \mathrm{~g} / \mathrm{cc}\right)^{2}$. It has good discriminative capacity for reservoir fluids. Low values (from 14.9 to $23.5(\mathrm{ft} / \mathrm{s} * \mathrm{~g} / \mathrm{cc})^{2}$ )are indicative of hydrocarbon-charged sands, while higher values $\left(>23.5\left(\mathrm{ft} / \mathrm{s}^{*} \mathrm{~g} / \mathrm{cc}\right)^{2}\right)$ indicate brine sands. Gas-charged sands have the lowest values of $\lambda \rho(<18.5)$. The well locations exhibit relatively low $\lambda \rho$ values, especially to the north of well A location. Data slice of MuRho is shown in Figure 15. Its values range from 4.31 to $17.17(\mathrm{ft} / \mathrm{s} * \mathrm{~g} / \mathrm{cc})^{2}$.Medium to high values $\left(\geq 5.0(\mathrm{ft} / \mathrm{s} * \mathrm{~g} / \mathrm{cc})^{2}\right)$ of Murho around well locations indicate hydrocarbon bearing sands. 


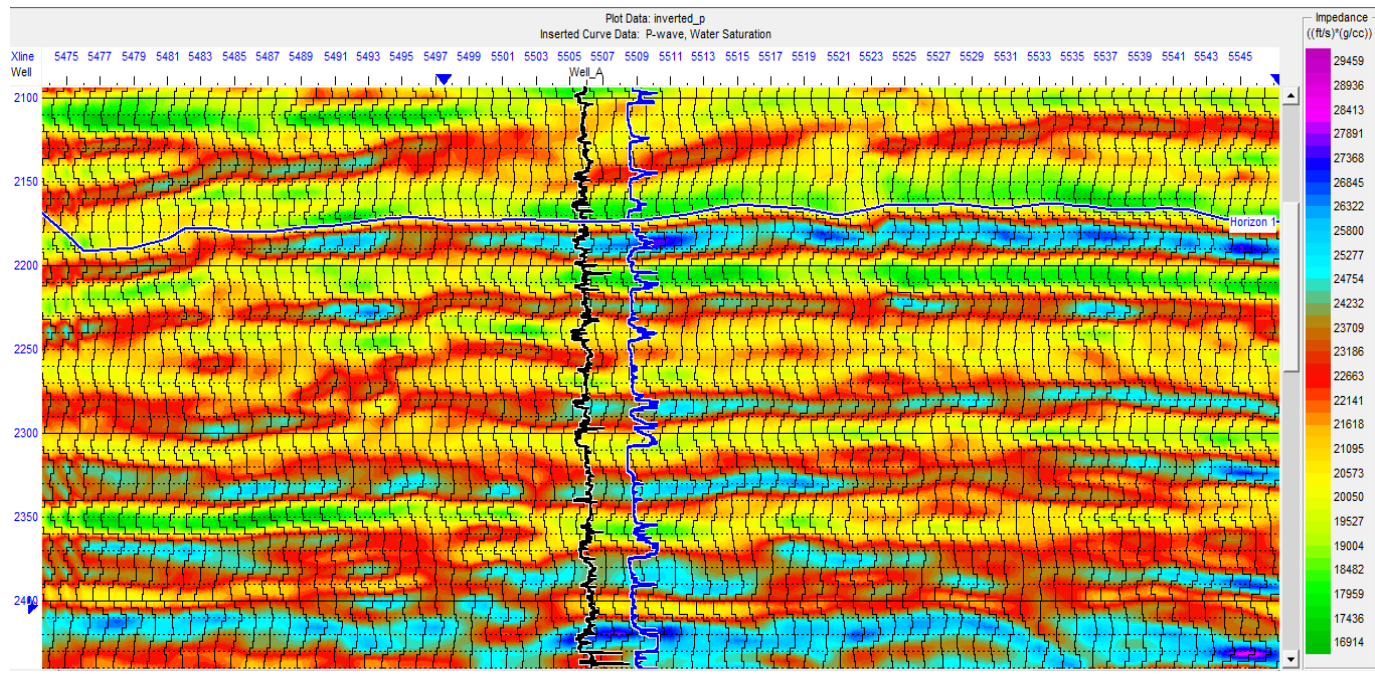

Figure 10. Inverted Acoustic Impedance volume

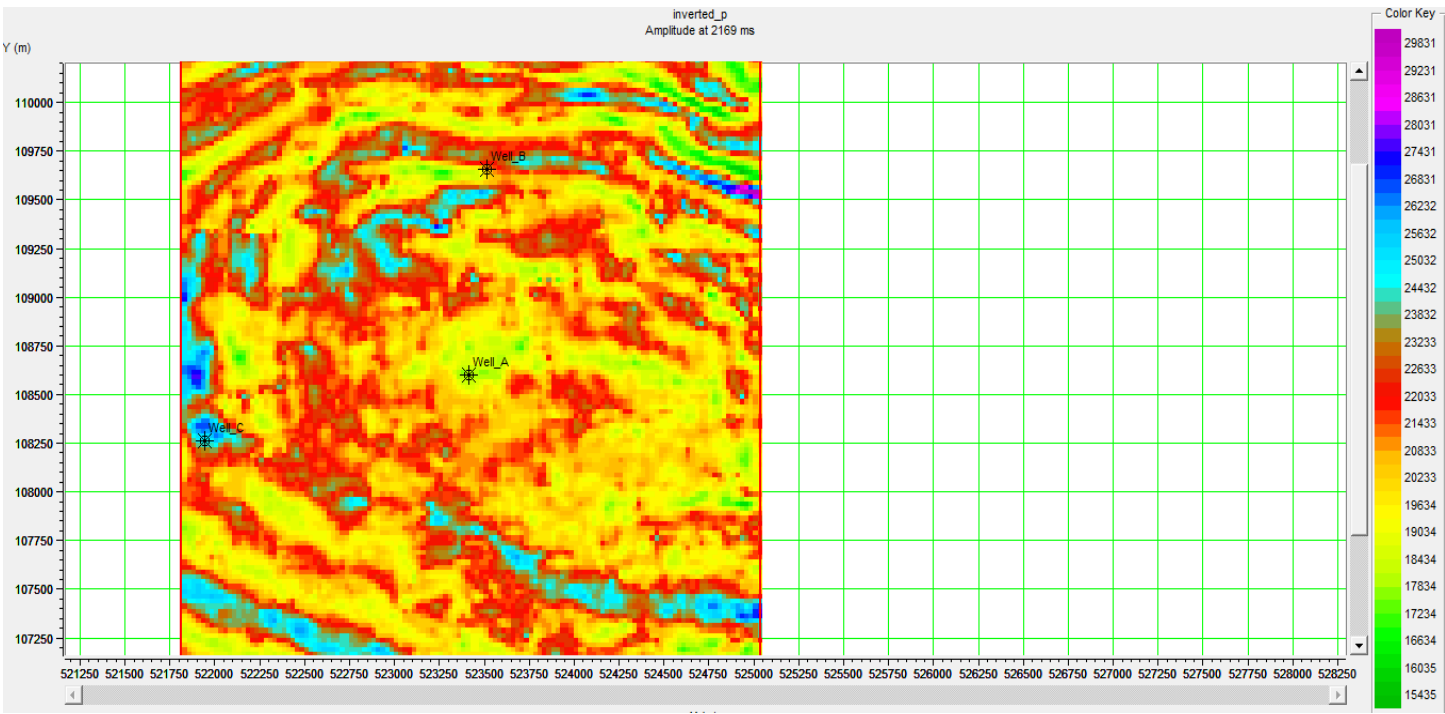

Figure 11. Data slice of Acoustic impedance

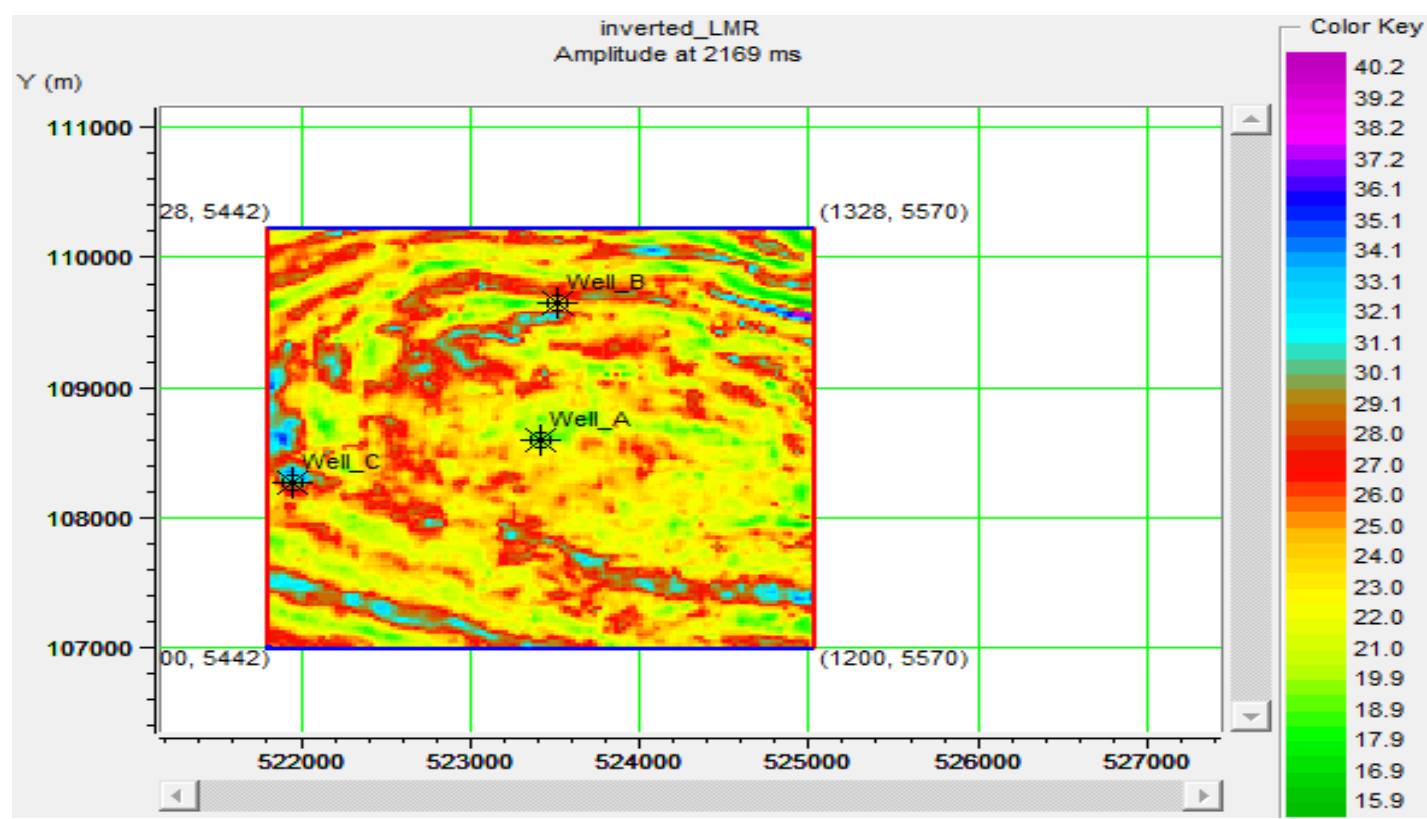

Figure 12.Inverted Lamda-Rho volume 


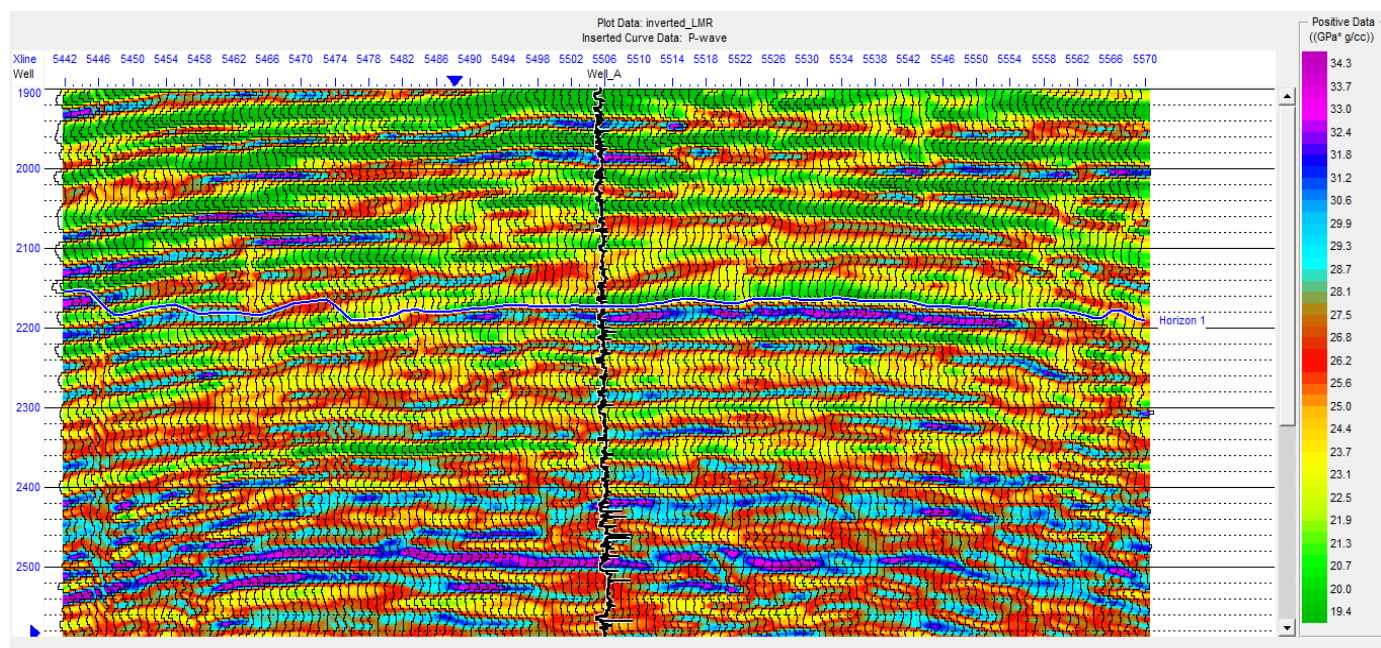

Time (ms)

Figure 13. Data slice of Lamda-Rho

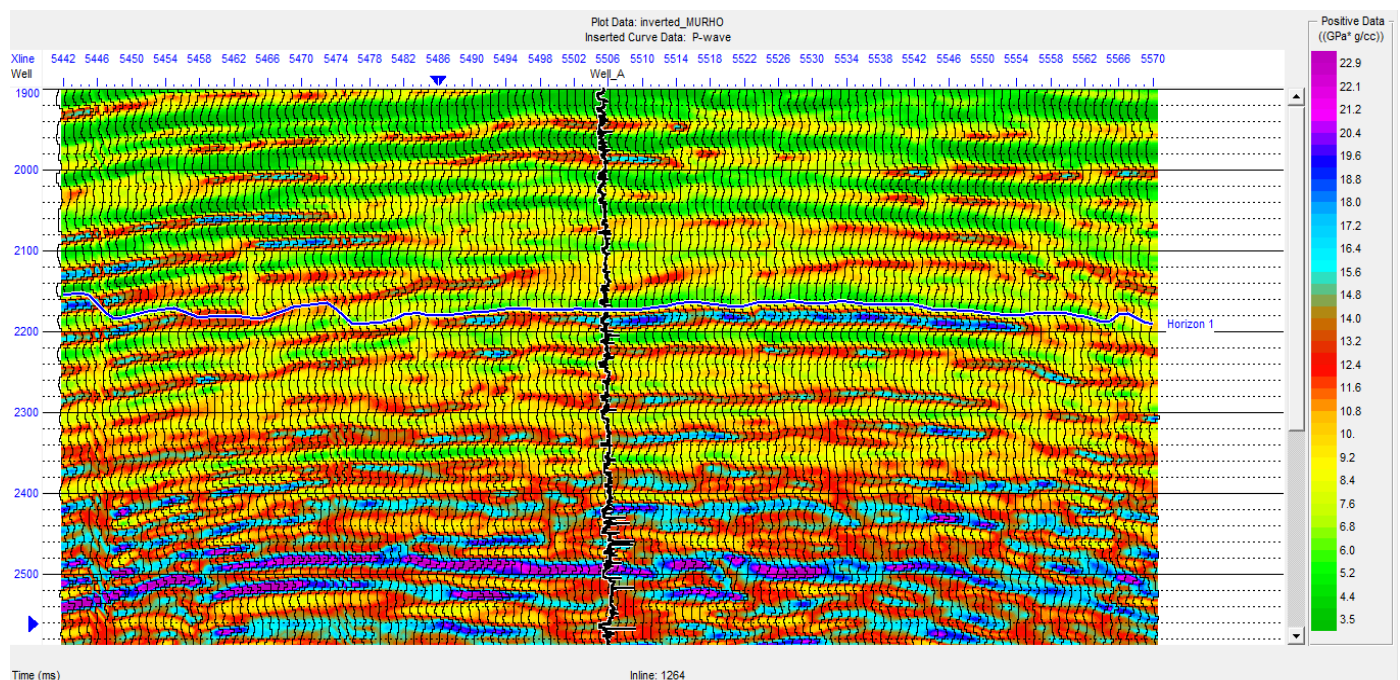

Figure 14.inverted $\mathrm{Mu}-\mathrm{Rho}$ volume

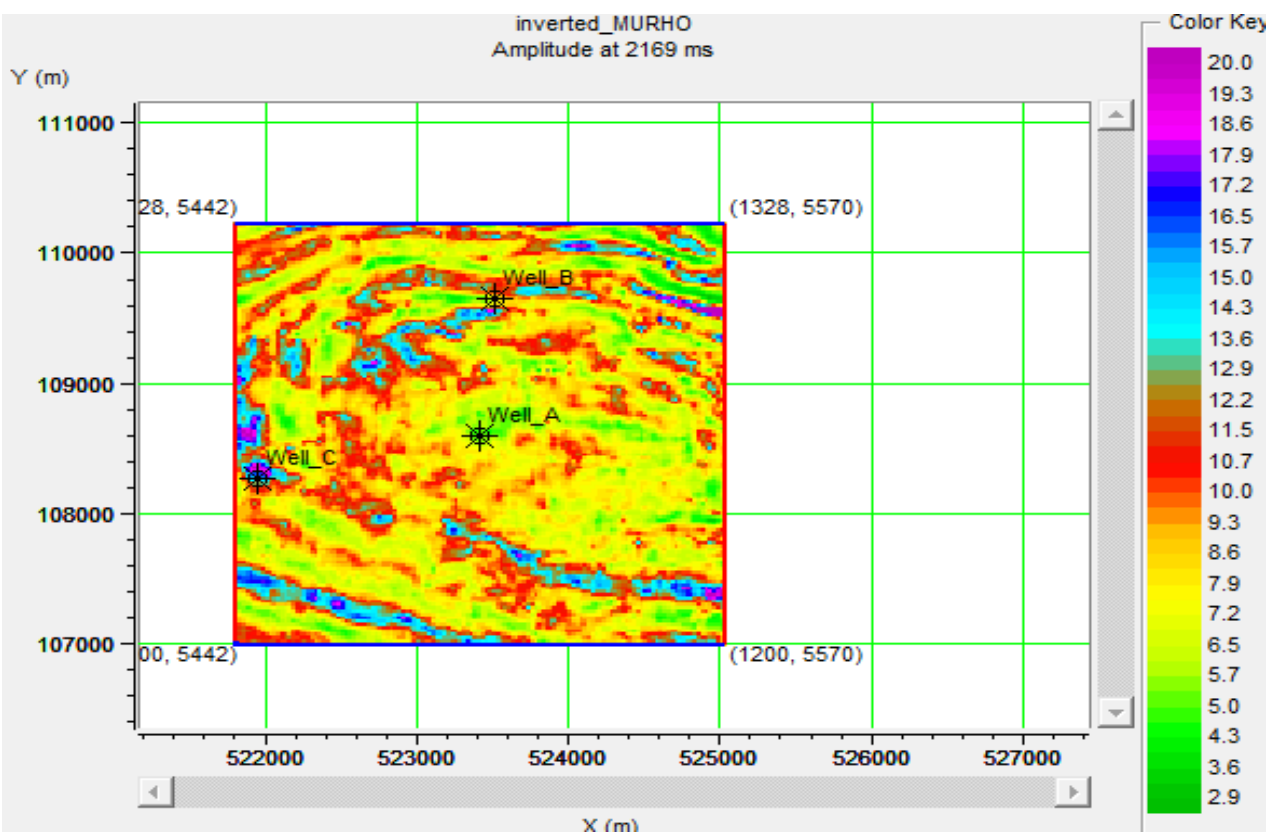

Figure 15. Data slice of Mu-Rho 


\section{Conclusion}

From the cross plots analysis, P-impedance, Lamda-rho and Mu-rho attributes were found to be most robust in lithology and fluid discrimination within the reservoir. The $\lambda-\mu-\rho$ technique was able to identify gas sands, because of the separation in responses of both $\lambda \rho$ and $\mu \rho$ sections to gas sands versus shale. Results from Lambda-Mu-Rho $(\lambda-\mu-\rho)$ inversion provided greater insight into rock properties for pore fluid and lithology discrimination by isolating Lamé impedance parameters (LambdaRho $(\lambda \rho)$ and MuRho $(\mu \rho)$ ) from the seismic reflectivity response. The combined interpretation of LambdaRho $(\lambda \rho)$ and MuRho $(\mu \rho)$ from the post-stack 3D seismic data set in the study area enhanced the identification and delineation of hydrocarbon charged sands with greater confidence. Low values of LambdaRho $(\lambda \rho)$, associated with moderate to high values of MuRho $(\mu \rho)$ indicate the presence of hydrocarbon within the sand reservoirs. These results thus confirm that this approach can be applied with confidence in delineating bye-passed hydrocarbon in other fields in the Niger Delta basin and thereby increase production from such fields.

\section{Acknowledgement}

The authors acknowledge SPDC Nigeria for the data used for this work.

\section{References}

[1]. Chopra, S., and J. P. Castagna, 2014, AVO: SEG Investigations in Geophysics Series No. 16, http://dx.doi. org/10.1190/1.9781560803201

[2]. Close, D., Taylor, R. and Nixon, S,. 2016. A case study in quantitative interpretation ambiguity, lambda-mu-rho, and rock-physics modeling in the Otway Basin, Australia. The Leading edge pp 43.

[3]. Doust, H., and Omatsola, E., 1990, Divergent/passive Margin Basins, AAPG Memoir 48: Tulsa, American Association of Petroleum Geologists, p. 239-248.

[4]. Fatti, J. L., Vail, P. J., Smith, G. C., Strauss, P. J., and Levitt, P. R., 1994, Detection of gas in sandstone reservoirs using AVO analysis: A 3-D seismic case history using the geostack technique: Geophysics, 59, 1362-1376.

[5]. Goodway, B., Chen, T., and Downton, J., 1997, Improved AVO fluid detection and lithology discrimination using Lame petrophysical parameters; $\lambda \rho, \mu \rho \& \lambda \rho / \mu \rho$ fluid stack, from P- and S- inversions: Presented at the 67 th Annual International Meeting, SEG, Expanded Abstracts, $183-.186$.

[6]. Haack, R.G; Sundaraman, P and Daal (1997): Niger Delta Petroleum system, in extended Abstracts, AAPG/ABGP Hedberg research symposium Petroleum systems of South Atlantic margin, November 16-19. Rio de Janeiro Brazil.

[7]. Sayers, C., and S. Chopra, 2009, Special session: Rock physics: The Leading Edge, p.15-16.

[8]. White, R.E. and Hu, T., 1998, How accurate can a well tie be? The Leading Edge 18(8), 1065-1071. 